\title{
The Integration and Application of Traditional Culture of Local Characteristics in Public Art Design
}

\author{
Shukui Song \\ Department of Digital Art \\ Dalian Neusoft University of Information \\ Dalian, China 116033
}

\begin{abstract}
Chinese traditional culture is broad and profound, and of a long history. It benefits oversea countries and the world. But we are at a starting stage in protecting and spreading our traditional culture. Other Asian countries attach importance to traditional culture of local characteristics through all kinds of cultural elements. European countries use the integrated method of original ecology and city to protect traditional culture of regional customs, which provide us previous cases to the integration and application of traditional culture of local characteristics. On the basis of analysis and integration of local customs and my own work cases, the author summed up the local traditional culture and experience should become an important resource of public art design and develop a suitable and innovative heritage road combining China's traditional cultural advantages.
\end{abstract}

Keywords—local characteristics; traditional culture; public art design; integration and innovation

\section{INTRODUCTION}

Local characteristics generally refer to the characteristics "others don't have but we have". They include living habits, diet culture, aesthetic taste, etiquette and custom, industrial products, agricultural products etc. formed by people living for a long term in certain area. These local characteristics can demonstrate the regional history, culture, folk customs and so on, and the important is that they can be as material cultural heritage and intangible cultural heritage for analysis, appreciation, research and heritage. For example, the Northeast has the eight major wonders, white mountains and black soil; Beijing has styles and features of Qing Dynasty, such as, alley, quadrangle courtyard, glassware, cloisonné and palace lanterns; Shanghai has lane, wood carving, vintage car and tramcar; Weifang has kites; Yunnan has variegated-copperware craft; Xi'an has ancient capital culture; Hangzhou has silk; Wuhan has the culture of Chu Dynasty; Guangdong has the culture of the Five Ridges, year-end flower market, new-year awaking lion and dragon boat. As time passes, they become the beautiful symbols of past generations. They make history become an important field in urban public art, which creates a tension through the reappearance of past time and the reality of normalization[1]. There are rich resources in national cultural tradition for mining, transformation, utilization, inheritance and spread. It includes both the intangible cultural heritage and the intangible cultural heritage, such as, totem symbol, spiritual temperament, conscious connotation, cultural deposits, cultural artistic conception, art media, creative techniques and language style. In the open contemporary era, public art can undertake many functions, including creating highquality public living space and environment, realizing cultural heritage and free communication, and even implementing social and cultural criticism[2].

\section{THE DEVELOPMENT OF LOCAL CHARACTERISTIC CUlTURE IN OUR COUNTRY}

The local characteristic culture is the soil and the foundation of the local regional culture and the economic development. At present, our country has prominent characteristic cultures, which are obviously distinctive between the north and south in a large scale. At the same time, local characteristics are also the key to the public art to establish their own aesthetic identification symbols. In terms of art, resistance to generality is always one of its essences. In many regions of China, there are unique traditional costumes, food, residential and transportation modes. They not only reflect the local historical accumulation, but also reflect the characteristics of the local natural environment. The natural environments of people living in different areas are also different, as well as climate and products. They have a profound impact on their clothing materials, styles, colors, etc., which is typically reflected in our national minority costumes. For example, Dai people living in tropical and subtropical regions, with humid climate and lush forests, generally wear silk-sewing narrow-sleeve jacket and drum skirt; Tibetans mainly live in the Tibetan Plateau, and generally wear Tibetan robe. The topography, climate and resources have a great influence on people's food materials, cooking methods and tastes. For example, it is subhumidsemiarid climate in northern China, so it is fertile of wheat and people generally eat wheaten food. It is moist climate in southern China, so there are mainly paddy fields and people generally eat rice. Their specialties are also generally made of rice. We have a vast territory and abundant resources. All regions have their own regional cultures which are deposits of time and history. At the same time, it sums up the development of local public culture. 


\section{THE SPREAD OF TRADitional CULTURE OF LOCAL CHARACTERISTICS IN PUBLIC ART DESIGN}

The spread of traditional culture is the bridge of art in reflecting the characteristics and meeting the public's aesthetic ability and interest. It can highly simplify the local aesthetic features, and satisfy the public's growing aesthetic taste. Public art design should be public art space design. The related fields include architectural design, industrial design, decorative art and design, ceramic design, city landscape design, plane mural design, art square and art sculpture park and residential community design. The functions of public art design is to disseminate culture, enhance the cultural identity and cultural sentiment of the public, construct the aesthetic space and atmosphere, so as to enhance the people's aesthetic ability and interest. Many foreign art galleries, museums, galleries and design works of public art fully proved this conception. Local characteristic culture has a complementary and interdependent relationship with the development of public art. Whether the cultural elements embodied in human and material content can be targeted in public art and design works lies in "the artistic reflection of abstract elements from public soil in design works" and showing unique charm. It can ultimately enhance the dissemination and inheritance intensity of the entire local traditional culture. When our social productive forces develop to a certain level, the public is not satisfied with the fast, monotonous and indifferent function space, but wants to build a more characteristic place. Therefore, the basic spatial modeling has been endowed with more emotional significance by "characteristics". It is not only a concrete "here", but also a place where all the stories and memories in people's life are created[3]. Experience, participation and interaction are the trends of future public art, and they are also the most fascinating and special significance. The public art design should be national, of times, interactive, functional, aesthetic, interactive, disseminated, extensive and localized. In the process of design, culture is materialized and continued and developed in a new form. The relation between traditional culture and modern design can be regarded as the relation between "source" and "stream", "root" and "leaf"[4]. Traditional culture is the foundation of modern public art space design. Public art design is an important part of the spiritual connotations of traditional culture. They mutually coordinate, interplay, support each other and develop jointly. Without qualities of national traditional culture and regional culture, the public art design will be misfits with the geographical and humane environment and folk customs. Then it will lose the existing meaning of public space [5].

\section{THE INTEGRATION AND INNOVATION OF Traditional CUlture AND PubliC ART DESign}

In the 19th Century, the great British writer and artist Oscar Wilde in The Decay of Lying pointed out that "life imitates art far more than art imitates life". It explains the influence of priority and guidance relationship between the art and tradition. The space works of public art has a close relationship with architectural design. Both of them are affected by the environment, and consistent with environment. Works shall source from environment and highly present life and arouse public sympathy. Traditional culture refers to languages, life and aesthetic habits the highly concentrated living communities passed down. "Its appearance is the materialized form of people's desire" [6]. Public art has "public character" and "artistic quality". How to integrate "tradition", "public" and "art" organically is a hot issue in modern culture, art, design and aesthetic fields. For example, our coastal cities take advantage of ocean culture of local characteristics (ocean trade culture) to skillfully integrate public art. Ocean, as a special local media and platform, undertakes the import and export responsibilities of products, economy and culture. Throughout the world economic development history, ocean culture and trade is an important medium to decide whether the cultural landing and export can be realized. The author's sculpture work Huge Port of the Yangtze River ("Fig. 1" in 2012 carried off a "Liu Kaiqu Prize" in the international sculpture exhibition. Meanwhile, it has been exhibiting in Wuhu Sculpture Park. With a special core geographical location, Wuhu is named as "famous city on the south of Yangtze River" and "well-known region of $\mathrm{Wu}$ and Chu". Mr. Sun Zhongshan named her "Huge Port of the Yangtze River and Backbone of Anhui Province", and hence is famous around the world. It is one of the earliest opening cities. It is a typical model of integration of Chinese and western. So, my sculpture style is based on traditional element (horse head wall) as the carrier, using contemporary expression technique and materials (stainless steel). Combing historical culture and characteristics of Wuhu, the work followed the lofty ideal and practice of Mr. Liu Kaiqu, integrating the western and eastern cultures. This sculpture shows the mutual integration of classical aura and modern civilization in hope city Wuhu. Wuhu is a humid land. It has many lakes and outstanding people. Facing the Yangtze River and Qingge River, it is an important wetland city in the lower stream of Yangtze River, so the author used the element of water in this work. The entire model adopts the style of "horse head wall", unique in Huizhou architecture. Uses stainless steel circle to support and sets water curtain under gray tiles. Under the water certain is wall style. If there is no water under the horse head wall, the stainless steel reflects the surrounding environment, as if it is a part of environment. And the grey tile looks more mysterious. People can rest and play around the circle. Place the circle on the grass, and stainless steel is fully integrated with the environment. If see from a distance, it looks like three sections of tile eaves, increasing the mystery of sculpture. At the same time, water flows along the top, implying the longstanding and endless Anhui culture. Facing the river, it progresses and develops. The author's sculpture work "Ruyi of Cloud and Water" "Fig. 2" in 2015 was selected and placed in Fuzhou Dongjiang Lake Park. This work shows the water-flowing culture of Minnan. Uses the design idea and concept of "image and form", and the style is huge Ruyi of auspicious clouds, like water of happiness flowing into the earth. It has the artistic conception that water of Fuzhou comes from the heaven. The sculpture is also like two auspicious trees, rooting in the treasure land of Fuzhou. The style of sculpture is full, smooth and coherent, as a maritime 
silk road, highlighting the strategic direction of "blue ocean economy" of Fuzhou. Meanwhile, it means to establish a deep friendship with cities along the marine silk road and to seek in-depth cooperation. Minnan culture attaches great importance to the use of cloud and water symbols. Benefiting from the marine economy and culture, Minnan gives water many symbolic meanings, such as wealth, intelligence and geomancy. As a kind of material culture characterized by mass, public art design should reflect folk custom and fully reflect local characteristics, so that it can be widely understood and accepted by the people [7]. As the international graphic designer Jin Daiqiang said in Uncle Jin Speaking - Design Quotations: "good design first should have good functions. Then it can give people more choice and methods to solve problem better. It is a creation. A creative design should be beautiful, innovative and has the value of appreciation and connotation. It can make people think and move people. Good design is a breakthrough, leading the trend, serving as a link between the past and future, and producing a far-reaching impact.[8]"

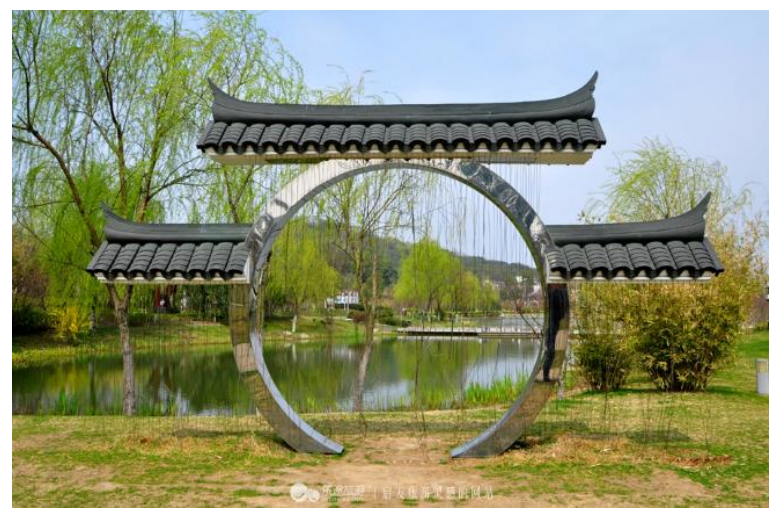

Fig. 1. Huge Port of the Yangtze River - Circle, Sculpture Work.

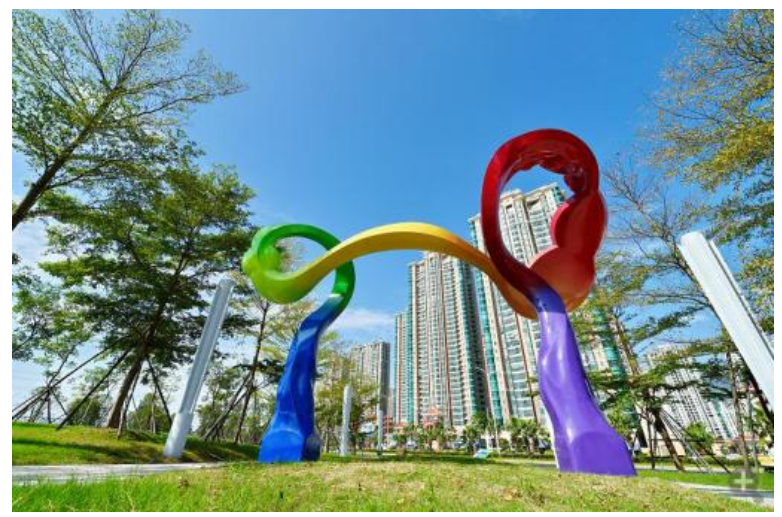

Fig. 2. Ruyi of Cloud and Water, Sculpture Work.

\section{CONCLUSION}

China's art and culture scholars Li Zhengqian et al. gives a definition of the relationship of culture and design in Art and Culture Interpretation of Contemporary Design: "culture, as a ideological representation symbol of human, is required to use specific symbols to express meaning. Design is the specific modeling behavior for human to use symbols to realize life ideals. This kind of behavior shall transform people's inner time image into specific perceptible form.[9]" Seen from the development trend of the world civilization, countries all over the world have list the transformation, transition, integration and innovation from traditional culture into modern culture as the strategic layout of the country's development, especially the world cultural export power America, China and other representative countries. In 1943 the famous American psychologist Maslow in A Theory of Human Motivation proposed five levels of human needs, from the lowest "basic needs" to "self realization". Since the reform and opening up, our comprehensive national strength and people's living standard are improved, and city urbanization continues to accelerate. The improvement of the urban public art design connotation and quality can fully embody the demand of "self-realization" in public consciousness. People are no longer satisfied with the simple functional and material wealth. They also require more pleasing visual effect and more spiritual connotation [10]. Good public art designs will be works can leave people a deep impression and arouse their sympathy. With the "cultural globalization" process and its increasing effect, "Chinese spirit and Chinese dream" advocating in the 13th Five-Year national planning boost inheritance of Chinese traditional culture; from local small scale, will the traditional culture and public art grafting has become a hot issue in cultural circles, circles and circles of design aesthetics from the macroscopic angle. From the microscopic angle, the integration of traditional culture and public art will become a hot issue in the culture, design and aesthetics circles.

\section{REFERENCES}

[1] Liu Chengji. Beauty and Aesthetics in Public Art of Modern City. Literature and Art Studies. 2010. 06: 113-119.

[2] Pi Daojian. Public Art: Concept Change, Function Development and Resource Utilization. Contemporary Art. 2005. 02: 35-38.

[3] Wei Xin. Public Art and Place Spirit. Decoration. 2015. 11: 41-43.

[4] Wang Jun. The Application of Chinese Traditional Culture in Public Art Design. Jilin University. 2008: 15.

[5] Jin Guosheng. Geographical and Cultural Characteristics and Differences in Public Art Field. New Arts. 2012. 03: 93-96.

[6] Liu Chengii. Beauty and Aesthetics in Public Art of Modern City. Literature and Art Studies. 2010. 06: 113-119.

[7] Lin Lan. The Relationship between Public Art and Regional Folklore Tradition. Decoration. 2016. 11: 42-42.

[8] Jin Daiqiang. Uncle Jin Speaking - Design Quotations. Anhui Fine Arts Publishing House. 2009. 9: 9.

[9] Li Zhengqian, Zhao Meng \& Li Jiansheng. Art and Culture Interpretation of Contemporary Design. Henan Art Publishing House, 1993: 210.

[10] Lin Lan. The Relationship between Public Art and Regional Folklore Tradition. Decoration. 2016. 11: 42-42. 